\title{
Peripheral Immune Alterations in Major Depression: The Role of Subtypes and Pathogenetic Characteristics
}

\section{Frank Euteneuer ${ }^{1 *}$, Katharina Dannehl', Adriana del Rey ${ }^{2}$, Harald Engler ${ }^{3}$, Manfred Schedlowski, ${ }^{3,4}$ and Winfried Rief'}

${ }^{1}$ Division of Clinical Psychology and Psychotherapy, Philipps University of Marburg, Marburg, Germany, ${ }^{2}$ Research Group Immunophysiology, Division of Neurophysiology, Institute of Physiology and Pathophysiology, Philipps University of Marburg, Marburg, Germany, ${ }^{3}$ Institute of Medical Psychology and Behavioral Immunobiology, University Hospital Essen, University of Duisburg-Essen, Essen, Germany, ${ }^{4}$ Department of Clinical Neuroscience, Karolinska Institutet, Stockholm, Sweden

Depression has been associated with peripheral inflammatory processes and alterations in cellular immunity. Growing evidence suggests that immunological alterations may neither be necessary nor sufficient to induce depression in general, but seem to be asso-

OPEN ACCESS

Edited by:

Brisa S. Fernandes,

Deakin University, Australia

Reviewed by:

Rebecca Strawbridge,

King's College London,

United Kingdom

Mirko Manchia,

Dalhousie University, Canada

${ }^{*}$ Correspondence:

Frank Euteneuer

frank.euteneuer@staff.uni-marburg.de

Specialty section:

This article was submitted to Mood and Anxiety Disorders,

a section of the journal

Frontiers in Psychiatry

Received: 05 October 2017 Accepted: 09 November 2017 Published: 23 November 2017

Citation:

Euteneuer F, Dannehl K, del Rey A, Engler $\mathrm{H}$, Schedlowski $M$ and Rief $W$ (2017) Peripheral Immune Alterations in Major Depression: The Role of Subtypes and Pathogenetic Characteristics.

Front. Psychiatry 8:250. doi: 10.3389/fpsyt.2017.00250 ciated with specific features. Using baseline data from the Outcome of Psychological Interventions in Depression trial, this exploratory study examines associations between depression subtypes and pathogenetic characteristics (i.e., melancholic vs non-melancholic depression, chronic vs non-chronic depression, age of onset, cognitive-affective and somatic symptom dimensions) with plasma levels of C-reactive protein (CRP), interleukin (IL)-6, IL-10, and numbers of leukocyte subpopulations in 98 patients with major depression (MD) and 30 age and sex-matched controls. Patients with MD exhibited higher CRP levels, higher neutrophil and monocyte counts, lower IL-10 levels, and an increased neutrophil to lymphocyte ratio (NLR) than controls. Patient with later age of onset had higher levels of two inflammatory markers (CRP, NLR) and lower cytotoxic $T$ cell counts after adjusting for sociodemographics, lifestyle factors, and antidepressants. Furthermore, lower anti-inflammatory $\mathrm{LL}-10$ levels were related to more severe somatic depressive symptoms. These results confirm and extend previous findings suggesting that increased levels of CRP are associated with a later onset of depression and demonstrate that also NLR as a subclinical inflammatory marker is related to a later onset of depression.

Keywords: age of onset, C-reactive protein, cytokines, depressive symptoms, depression subtypes, leukocytes

\section{INTRODUCTION}

Depression has been associated with peripheral immune alterations, in particular low-grade inflammation $(1,2)$. Longitudinal and experimental studies in humans and animals suggest bidirectional immune-to-brain communications, in which inflammation-associated disorders (e.g., cardiovascular disease, metabolic syndrome) and peripheral inflammatory signals lead to depressive symptoms and vice versa (3-7). 
Importantly, meta-analyses on depression and inflammation suggest a large heterogeneity across studies $(1,2)$. This heterogeneity may result, in part, from methodological differences and limitations, for example, no consideration of important confounders, inadequate data preparation, or different ways to measure depression. Moreover, heterogeneity may reflect that depression is not a "natural kind" but rather a scientific taxonomic category with substantial within-category variation (8). Confirming this perspective, growing evidence suggests that inflammation may neither be necessary nor sufficient to induce or sustain depression in general, but may be associated with specific subtypes and characteristics of depression, respectively (5). For example, some studies (9-11), but not all (12), suggest that inflammation may be particularly associated with somatic depressive symptoms. Other studies indicate that a later age of onset (13) may relate to higher levels of inflammatory markers, while findings for specific depression subtypes are mixed (14-19).

For immunological measures beside circulating inflammatory markers, results for depression seem to be even more heterogeneous and associations with disease characteristics are understudied. These inconsistencies involve studies on immune cells counts and distributions $(20,21)$. In addition, results for circulating anti-inflammatory interleukin (IL)-10 are mixed $(1,22,23)$, although findings in chronic heart failure (24), renal disease (25), and also animal research (26-31) clearly suggest a link between reduced IL-10 and depression.

Using baseline data from the Outcome of Psychological Interventions in Depression (OPID)-trial (32), this exploratory study examined whether specific depression subtypes [melancholic vs non-melancholic (i.e., atypical or unspecified), chronic vs non-chronic] and characteristics (symptom severity, age of onset) are associated with pro- and anti-inflammatory parameters and leukocyte subsets distribution.

\section{MATERIALS AND METHODS}

\section{Participants and Procedure}

Data were selected from baseline assessments of the OPID-trial, funded by the German Research Foundation (DFG RI 574/231, SCHE 341/20-1) to WR and MS, respectively. As described previously (32), 98 patients aged 18-65 who fulfilled criteria for major depression (MD) in DSM-IV (33) and a sample of 30 ageand sex-matched healthy controls from the same community were included. Patients were recruited via the Outpatient Clinic for Psychological Interventions of the University of Marburg, via advertisements, leaflets in pharmacies, and waiting rooms of doctors, as well as press releases in local newspapers. Healthy controls were recruited via advertisements and press releases in local newspapers. Written informed consent was obtained from all participants.

After prescreening via phone, participants underwent a diagnostic session with a clinical psychologist that included the German version of the structured clinical interview for DSM-IV (SCID) (34) and an interview to assess the medical history, potential exclusion criteria, sociodemographics, and several health-related variables. Exclusion criteria were neurological illness, psychotic symptoms, injuries, and infections during the last 14 days, alcohol and/or drug abuse, systemic corticosteroids, antipsychotics, stimulants, current pregnancy and lactation in women, and any mental disorders according to DSM-IV for healthy controls. Because patients with depression were considered for further psychological treatment, they also underwent a physical examination by a physician as requested by German health insurances. Patients who took antidepressants were considered for participation under the assumption that the dose had been stable for at least 2 weeks and would remain so during study participation. After diagnostic sessions and giving informed consent, individuals were invited for blood withdrawal and psychometric measures on the following days.

Pathogenetic characteristics (i.e., melancholic vs nonmelancholic depression, chronic vs non-chronic depression, age of onset) were examined during the SCID interview. If available, information from previous doctor visits or hospital reports were also considered. Total depressive symptom severity and scores for cognitive-affective and somatic symptoms (35) were assessed with the German version of the Beck Depression Inventory (BDI)-II (36). The long version of the International Physical Activity Questionnaire (37) was used to assess metabolic equivalent minutes per week (MET-min/week) for total physical activity and three domains (walking, moderate-intensity, and vigorous-intensity).

\section{Immunological Measures}

Before blood sampling, participants were queried about acute infections during the last 14 days, chronic infections, or illness, and a sample was considered missing if participants reported any one of these issues. Participants were instructed to avoid exercise and alcohol $24 \mathrm{~h}$ prior to blood withdrawal. Non-fasting blood samples were collected in EDTA-treated or heparinized tubes (S-Monovette, Sarstedt, Nümbrecht, Germany) between 7:00 a.m. and 10:00 a.m. Plasma for C-reactive protein (CRP) and cytokine measurements were separated by centrifugation at $2,000 \times g$ for $10 \mathrm{~min}$ at $4^{\circ} \mathrm{C}$, and plasma was stored at $-80^{\circ} \mathrm{C}$ (7-12 months) until analysis. CRP was measured using an enzyme-linked immunosorbent assay (CRP high-sensitive ELISA, IBL International, Hamburg, Germany) according to the manufacturer's instructions. Plasma levels of IL-6 and IL-10 were analyzed by flow cytometry using bead-based assays (Bio-Plex Pro Human Cytokine Assays, Bio-Rad Laboratories, Hercules, CA, USA) as previously described (38). The sensitivity of the assays was $0.02 \mu \mathrm{g} / \mathrm{ml}$ for CRP, $0.45 \mathrm{pg} / \mathrm{ml}$ for IL-6, and $0.59 \mathrm{pg} / \mathrm{ml}$ for IL-10. Undetectable IL-6 $(n=1)$ and IL-10 $(n=4)$ were assigned a value of the limit of detection divided by (LOD/2). Complete blood counts including the white blood cell differential were obtained using an automated hematology analyzer (XT-2000i, Sysmex, Horgen, Switzerland). Leukocyte subpopulations were determined by flow cytometry using a standard lyse/wash procedure and the following antibodies (all from BioLegend, San Diego, CA, USA): FITC-conjugated antihuman CD3 (clone SK7), Pacific Blue-conjugated anti-human CD4 (clone SK3), PE-Cy7-conjugated anti-human CD8 (clone SK1), APC-Cy7-conjugated anti-human CD14 (clone M5E2), PerCP-Cy5.5-conjugated anti-human CD19 (clone HIB19), 
PE-conjugated anti-human CD25 (clone BC96), PE-conjugated anti-human CD56 (clone MEM-188), and AF647-conjugated anti-human CD127 (clone A019D5). Samples were analyzed on a FACSCanto II flow cytometer (BD Biosciences, Heidelberg, Germany) using BD FACSDiva software (Version 8.0.1, BD Biosciences).

\section{Statistical Analysis}

Statistical analyses were carried out with Mplus7 (Muthén and Muthén, 1998-2012) and IBM SPSS version 23.0 for Windows (Chicago, SPSS, Inc.). Missing values occurred due to heterogeneous technical problems, and extreme outliers in immunological variables were also considered missing values (i.e., values more than three interquartile ranges above the 75 th percentile) (39). Immunological data were available as follows: CRP (88\%), IL-6 (82\%), IL-10 (77\%), and leukocyte counts and subsets (83-91\%). Differences in group characteristics were calculated using pairwise comparisons with $\chi^{2}$ tests and $t$-tests, if necessary with Welch's correction in case of variance heterogeneity. Associations of depression subtypes and pathogenetic characteristics with immunological measures were analyzed with multiple regression analyses. Associations were examined without adjustment (model 1), with adjustment for sociodemographics (i.e., sex, age; model 2), and with additional adjustment for lifestyle factors (i.e., number of cigarettes/day, body mass index, physical activity; model 3) and antidepressants. Post hoc power analysis for linear regression (40) indicated a power of $96.7 \%$ with a medium effect size and an alpha of.05. To strengthen robustness and to handle missing data in multivariate analyses, regressions were based on full information maximum likelihood estimation with robust standard errors (MLR). Given the exploratory nature of this study, analyses were not corrected for multiple testing (41).

\section{RESULTS}

\section{Immunological Alterations in MD}

Table 1 shows characteristics of patients with MD and controls. Patients exhibited significantly higher levels of CRP, lower

TABLE 1 | Characteristics of patients with MD and controls.

\begin{tabular}{|c|c|c|c|}
\hline & MD $(n=98)$ & Controls $(n=30)$ & $t$ or $\chi^{2} ; p$ \\
\hline Age & $37.3(12.2)$ & $37.1(12.2)$ & $0.08 ; 0.939$ \\
\hline Female, $n(\%)$ & 48 (49.0) & $15(50.0)$ & $0.01 ; 0.922$ \\
\hline $\begin{array}{l}\text { Body mass } \\
\text { index, } \mathrm{kg} / \mathrm{m}^{2}\end{array}$ & $26.1(5.3)$ & $24.0(4.2)$ & $1.96 ; 0.052$ \\
\hline Education (years) & $11.3(1.7)$ & $12.2(1.5)$ & $-2.83 ; 0.006$ \\
\hline $\begin{array}{l}\text { Number of } \\
\text { cigarettes/day }\end{array}$ & $3.0(7.1)$ & $0.5(1.9)$ & $1.90 ; 0.060$ \\
\hline \multicolumn{4}{|l|}{$\begin{array}{l}\text { Antidepressant } \\
\text { medication, } n(\%)\end{array}$} \\
\hline Total & 37 (37.8) & - & - \\
\hline SSRIS & 15 (15.3) & - & - \\
\hline SNRIs & $6(6.1)$ & - & - \\
\hline Agomelatine & $5(5.1)$ & - & - \\
\hline
\end{tabular}

(Continued)
TABLE 1 | Continued

\begin{tabular}{|c|c|c|c|}
\hline & MD $(n=98)$ & Controls $(n=30)$ & $t$ or $\chi^{2} ; p$ \\
\hline NaSSAs & $5(5.1)$ & - & - \\
\hline TCAs & $5(5.1)$ & - & - \\
\hline St John's wort & $3(3.1)$ & - & - \\
\hline NDRIs & $1(1.0)$ & - & - \\
\hline \multicolumn{4}{|l|}{$\begin{array}{l}\text { Depressive symptom } \\
\text { severity, BDI-II }\end{array}$} \\
\hline Total score & $26.9(9.1)$ & $4.6(5.5)$ & $18.26 ;<0.001$ \\
\hline $\begin{array}{l}\text { Cognitive-affective } \\
\text { symptoms }\end{array}$ & $19.3(7.6)$ & $2.7(1.9)$ & $15.56 ;<0.001$ \\
\hline Somatic symptoms & $7.2(2.6)$ & $1.9(1.9)$ & $12.35 ;<0.001$ \\
\hline \multicolumn{4}{|l|}{$\begin{array}{l}\text { DSM-IV axis I } \\
\text { comorbidity, } n \text { (\%) }\end{array}$} \\
\hline Anxiety disorders & $23(23.5)$ & - & - \\
\hline $\begin{array}{l}\text { Somatoform } \\
\text { disorders }\end{array}$ & $12(12.2)$ & - & - \\
\hline \multicolumn{4}{|l|}{ Subtypes, $n(\%)$} \\
\hline Melancholic MD & $51(52.0)$ & - & - \\
\hline $\begin{array}{l}\text { Chronic MD } \\
\text { ( } \geq 2 \text { years) }\end{array}$ & $41(41.8)$ & - & - \\
\hline $\begin{array}{l}\text { Age of depression } \\
\text { onset }\end{array}$ & $28.36(12.7)$ & - & - \\
\hline \multicolumn{4}{|l|}{$\begin{array}{l}\text { Physical activity, } \\
\text { IPAQ, MET-min/week }\end{array}$} \\
\hline Walking & $1,364.8(1,392.5)$ & 1,919.5 (2,020.6) & $-1.61 ; 0.092$ \\
\hline $\begin{array}{l}\text { Moderate-intensity } \\
\text { activity }\end{array}$ & $2,040.0(2,227.0)$ & $2,243.8(2,813.1)$ & $-0.87 ; 0.388$ \\
\hline $\begin{array}{l}\text { Vigorous-intensity } \\
\text { activity }\end{array}$ & $861.1(1,670.6)$ & $1,577.3(1,739.28)$ & $-2.03 ; 0.045$ \\
\hline Total & $4.26(3.56)$ & $5.97(5.72)$ & $-1.55 ; 0.130$ \\
\hline $\mathrm{CRP}, \mu \mathrm{g} / \mathrm{ml}$ & $1.7(1.8)$ & $0.8(0.6)$ & $4.01 ;<0.001$ \\
\hline IL-6, pg/ml & $3.9(5.1)$ & $5.9(7.8)$ & $-1.22 ; 0.230$ \\
\hline IL-10, pg/ml & $5.8(9.2)$ & 12.9 (16.3) & $-2.09 ; 0.045$ \\
\hline IL-6/IL-10 ratio & $1.0(0.9)$ & $0.6(0.4)$ & $2.71 ; 0.008$ \\
\hline \multicolumn{4}{|l|}{ Immune cell counts $/ \mu$ | } \\
\hline Leukocytes & $6,780(1,889)$ & $6,740(2,209)$ & $0.69 ; 0.924$ \\
\hline Lymphocytes & 2,152 (669) & 2,286 (679) & $-0.82 ; 0.413$ \\
\hline Neutrophils & $4,099(1,420)$ & 3,520 (989) & $2.15 ; 0.038$ \\
\hline Monocytes & $403(134)$ & 310 (153) & $2.78 ; 0.006$ \\
\hline Total T cells & $1,454(541)$ & $1,494(460)$ & $-0.31 ; 0.761$ \\
\hline T helper cells & $948(427)$ & $920(372)$ & $0.27 ; 0.789$ \\
\hline Cytotoxic T cells & $426(188)$ & $485(147)$ & $-1.34 ; 0.184$ \\
\hline Regulatory T cells & $87(41)$ & $73(28)$ & $1.93 ; 0.061$ \\
\hline B cells & $236(147)$ & $197(94)$ & $1.38 ; 0.169$ \\
\hline NK cells & $258(147)$ & $281(128)$ & $-0.65 ; 0.516$ \\
\hline $\begin{array}{l}\text { Neutrophils/ } \\
\text { lymphocytes ratio }\end{array}$ & $2.0(0.7)$ & $1.6(0.6)$ & $2.50 ; 0.017$ \\
\hline
\end{tabular}

Values are mean (SD) unless noted with percentage. Group differences were calculated using $\chi^{2}$ tests for categorical variables and $t$-tests for continues variables. BDI, Beck Depression Inventory; CRP, C-reactive protein; DSM, Diagnostic and Statistical Manual of Mental Disorders; HC, healthy control group; IL, interleukin; IPAQ, International Physical Activity Questionnaire; MD, major depression; MET, metabolic equivalent; NDRIs, norepinephrine-dopamine reuptake inhibitor; NaSSAs, noradrenergic and specific serotonergic antidepressants; SNRIs, serotoninnorepinephrine reuptake inhibitors; SSRI, selective serotonin reuptake inhibitors; TCAs, tricyclic antidepressants.

levels of circulating IL-10, as well as higher IL-6/IL-10 ratios, compared to controls. Furthermore, neutrophil counts, monocyte counts, and neutrophil to lymphocyte ratio (NLR) were higher in patients than in controls. There were no significant 
differences between groups for any other immunological measures.

\section{Association of Depression Subtypes and Pathogenetic Characteristics with Immunological Measures}

As illustrated in Figure 1, age of depression onset was associated with two inflammatory markers. Unadjusted models indicated that patients with later age of onset exhibit higher levels of CRP $(\beta=0.326, p=0.002)$. After adjustment for age and sex, patients with later age of onset had higher levels of $\operatorname{CRP}(\beta=0.314, p=0.008)$ and $\operatorname{NLR}(\beta=0.296, p=0.012)$. Both associations remained significant, even after full adjustment for lifestyle factors and antidepressants (CRP: $\beta=0.334$, $p=0.002$; NLR: $\beta=0.245, p=0.033$ ). Furthermore, although no differences in cytotoxic $\mathrm{T}$ cells were observed between patients and controls, cytotoxic $\mathrm{T}$ cells were reduced in patients with later age of onset in unadjusted models $(\beta=-0.232$, $p=0.011)$ and after controlling for sex and age $(\beta=-0.317$, $p=0.014$ ), as well as for lifestyle factors and antidepressants $(\beta=-0.305, p=0.025)$. When looking at associations between immune markers related to age of onset, we found an inverse relationship between NLR and cytotoxic T cells $(\beta=-0.308$, $p<0.001)$. CRP was neither significantly associated with NLR $(\beta=-0.087, p=0.403)$ nor with cytotoxic T cells $(\beta=0.109$, $p=0.270)$.

Finally, we found that patients with higher levels of somatic depressive symptoms had lower levels of IL-10 after adjusting for sex and age $(\beta=-0.209, p=0.017)$ and additionally adjusting for lifestyle factors and antidepressants $(\beta=-0.238, p=0.038)$. Immunological measures were not significantly related to any other subtypes or characteristics (see Table S1 in Supplementary Material). Since some previous work on depression and inflammation indicates sex-related association patterns $(11,13,42)$, the role of sex was examined in exploratory moderation analyses resulting in no significant interactions.

\section{DISCUSSION}

The aim of this report was to examine whether pro- and antiinflammatory cytokines and circulating leukocyte subpopulations are associated with specific subtypes and characteristics in MD. As reported and discussed previously (32), patients in this study exhibited higher levels of CRP, lower levels of circulating IL-10, as well as higher IL-6/IL-10 ratios, compared to controls. In addition, neutrophil counts, monocyte counts, and NLR were increased in MD. Our main findings are that patients with later onset of depression exhibit higher levels of two inflammatory markers (i.e., CRP, NLR) and lower levels of cytotoxic T cells after adjusting for sociodemographics, lifestyle factors, and antidepressant medication. We further found that patients with lower levels of anti-inflammatory IL-10 had more severe somatic depressive symptoms.

Our result of an association between CRP and age of depression onset supports previous findings from the Netherlands Study of Depression and Anxiety (NESDA) including a large sample of patients with depression (13). While this study reported that CRP is related to age of onset only in men, we did not observe a moderating role for sex. A simple explanation for this inconsistency might be that women in the NESDA study had a significantly earlier age of depression onset compared to men. In contrast, age of depression onset in our study was comparable between men and women $(p=0.764)$.

In this study, NLR as a marker of subclinical inflammation was increased in patients with MD supporting recent observations $(43,44)$. Similar to CRP, NLR was related to a later onset of depression. In $\mathrm{MD}$, a later age of onset has not only been associated with inflammation (13), but also with atherosclerosis $(45,46)$. Also,

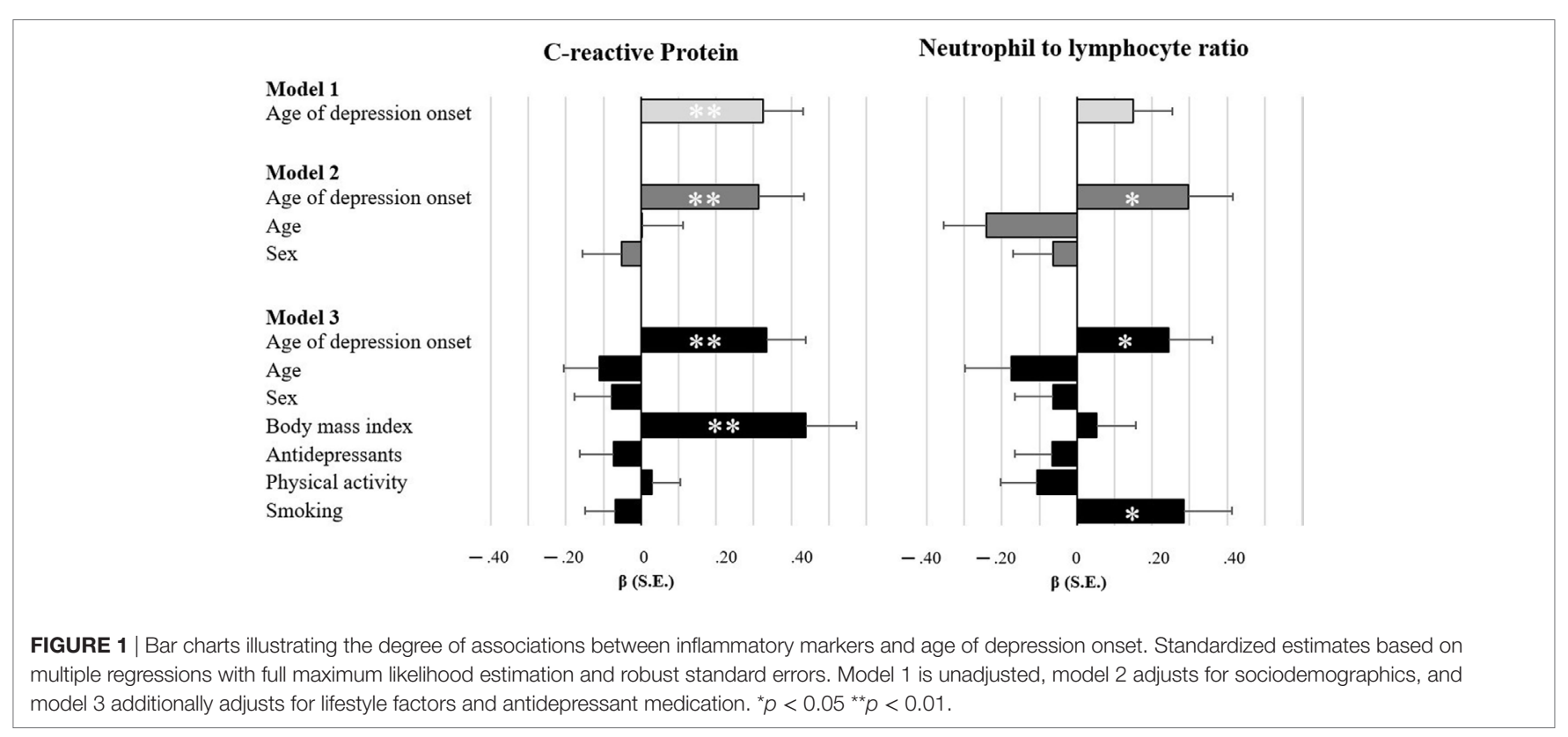


Kendler et al. (47) found two distinct sets of familial risk factors for MD. While an earlier age of onset was associated with a family history of depression, a later age of onset was associated with a family history of vascular disease. Thus, our findings might be in line with the vascular depression hypothesis as one distinct etiopathological mechanism and support the notion that a later onset of depression is associated with pathological pathways relevant for cardiovascular disease (13).

In this study, lower anti-inflammatory IL-10 was associated with more severe somatic depressive symptom. This finding needs further confirmation, but may be of interest in view of studies demonstrating antinociceptive effects of IL-10 (48) and amplified exhaustion and motor deficits in IL-10-deficient mice after bacterial challenge (49). In contrast to previous work, we did not find evidence for specific associations of inflammatory markers with somatic depressive symptoms (9-11) or depression subtypes (14-19). The reasons for these inconsistencies are unclear, but may relate to differences in study populations and assessment instruments.

This study has important strengths such as the analysis of a wide range of immunological parameters, clinical diagnoses of depression, exclusion of confounding medical conditions, and systematic consideration of potential theoretical confounders. Several limitations should be considered in interpreting our results. First, given the exploratory design of this study, further confirmatory research is necessary. Further limitations are the cross-sectional design and relatively small sample sizes for specific subgroups of patients. Moreover, our sample consisted of outpatients with MD. Thus, findings may not generalize to other samples of patients.

In conclusion, these results confirm and extend previous findings suggesting that increased levels of CRP are associated

\section{REFERENCES}

1. Dowlati Y, Herrmann N, Swardfager W, Liu H, Sham L, Reim EK, et al. A meta-analysis of cytokines in major depression. Biol Psychiatry (2010) 67:446-57. doi:10.1016/j.biopsych.2009.09.033

2. Howren MB, Lamkin DM, Suls J. Associations of depression with C-reactive protein, IL-1, and IL-6: a meta-analysis. Psychosom Med (2009) 71:171-86. doi:10.1097/PSY.0b013e3181907c1b

3. Stewart JC, Rand KL, Muldoon MF, Kamarck TW. A prospective evaluation of the directionality of the depression-inflammation relationship. Brain Behav Immun (2009) 23:936-44. doi:10.1016/j.bbi.2009.04.011

4. Miller AH, Raison CL. The role of inflammation in depression: from evolutionary imperative to modern treatment target. Nat Rev Immunol (2015) 16:22-34. doi:10.1038/nri.2015.5

5. Kiecolt-Glaser JK, Derry HM, Fagundes CP. Inflammation: depression fans the flames and feasts on the heat. Am J Psychiatry (2015) 172:1075-91. doi:10.1176/appi.ajp.2015.15020152

6. Williams ED, Steptoe A. The role of depression in the etiology of acute coronary syndrome. Curr Psychiatry Rep (2007) 9:486-92. doi:10.1007/ s11920-007-0066-y

7. Engler H, Brendt P, Wischermann J, Wegner A, Rohling R, Schoemberg T, et al. Selective increase of cerebrospinal fluid IL-6 during experimental systemic inflammation in humans: association with depressive symptoms. Mol Psychiatry (2017) 22:1448-54. doi:10.1038/mp.2016.264

8. Zachar P. Psychiatric disorders: natural kinds made by the world or practical kinds made by us? World Psychiatry (2015) 14:288-90. doi:10.1002/ wps. 20240 with a later onset of depression and demonstrate that also NLR as a subclinical inflammatory marker is related to a later onset of depression.

\section{ETHICS STATEMENT}

This study was approved by the German Psychological Society Review Board and was in accordance with the International Ethical Guidelines and Declaration of Helsinki. All methods were performed in accordance with the relevant guidelines and regulations.

\section{AUTHOR CONTRIBUTIONS}

WR and MS were primary investigators. WR, MS, HE, and FE designed and prepared the study. HE and AR prepared and supervised laboratory analyses. $\mathrm{KD}$ and $\mathrm{FE}$ coordinated data collection. FE wrote the main manuscript text. All authors reviewed the manuscript and contributed to the manuscript text.

\section{FUNDING STATEMENT}

This research was supported by a grant of the German Research Foundation (DFG RI 574/23-1, SCHE 341/20-1) to WR and MS, respectively.

\section{SUPPLEMENTARY MATERIAL}

The Supplementary Material for this article can be found online at http://www.frontiersin.org/article/10.3389/fpsyt.2017.00250/ full\#supplementary-material.
9. Duivis HE, Vogelzangs N, Kupper N, de Jonge P, Penninx BWJH. Differential association of somatic and cognitive symptoms of depression and anxiety with inflammation: findings from the Netherlands Study of Depression and Anxiety (NESDA). Psychoneuroendocrinology (2013) 38:1573-85. doi:10.1016/j. psyneuen.2013.01.002

10. Euteneuer F, Schwarz MJ, Dannehl K, Hartung A, Westermann S, Rief W. Increased soluble interleukin-2 receptor levels are related to somatic but not to cognitive-affective features in major depression. Brain Behav Immun (2012) 26(8):1244-8. doi:10.1016/j.bbi.2012.06.007

11. Dannehl K, Rief W, Schwarz MJ, Hennings A, Riemer S, Selberdinger V, et al. The predictive value of somatic and cognitive depressive symptoms for cytokine changes in patients with major depression. Neuropsychiatr Dis Treat (2014) 10:1191-7. doi:10.2147/NDT.S61640

12. Einvik G, Vistnes M, Hrubos-Strøm H, Randby A, Namtvedt SK, Nordhus IH, et al. Circulating cytokine concentrations are not associated with major depressive disorder in a community-based cohort. Gen Hosp Psychiatry (2012) 34:262-7. doi:10.1016/j.genhosppsych.2012.01.017

13. Vogelzangs N, Duivis HE, Beekman ATF, Kluft C, Neuteboom J, Hoogendijk W, et al. Association of depressive disorders, depression characteristics and antidepressant medication with inflammation. Transl Psychiatry (2012) 2:e79. doi:10.1038/tp.2012.8

14. Karlović D, Serretti A, Vrkić N, Martinac M, Marčinko D. Serum concentrations of CRP, IL-6, TNF- $\alpha$ and cortisol in major depressive disorder with melancholic or atypical features. Psychiatry Res (2012) 198:74-80. doi:10.1016/j. psychres.2011.12.007

15. Dunjic-Kostic B, Ivkovic M, Radonjic NV, Petronijevic ND, Pantovic M, Damjanovic A, et al. Melancholic and atypical major depression - connection 
between cytokines, psychopathology and treatment. Prog Neuropsychopharmacol Biol Psychiatry (2013) 43:1-6. doi:10.1016/j.pnpbp.2012.11.009

16. Lamers F, Vogelzangs N, Merikangas KR, de Jonge P, Beekman ATF, Penninx BWJH. Evidence for a differential role of HPA-axis function, inflammation and metabolic syndrome in melancholic versus atypical depression. Mol Psychiatry (2013) 18:692-9. doi:10.1038/mp.2012.144

17. Sowa-Kućma M, Styczeń K, Siwek M, Misztak P, Nowak RJ, Dudek D, et al. Lipid peroxidation and immune biomarkers are associated with major depression and its phenotypes, including treatment-resistant depression and melancholia. Neurotox Res (2017). doi:10.1007/s12640-017-9835-5

18. Maes M, Scharpé S, Meltzer HY, Bosmans E, Suy E, Calabrese J, et al. Relationships between interleukin- 6 activity, acute phase proteins, and function of the hypothalamic-pituitary-adrenal axis in severe depression. Psychiatry Res (1993) 49:11-27. doi:10.1016/0165-1781(93)90027-E

19. Erdem M, Celik C, Cayci T, Ozdemir B, Kurt YG, Akgul EO, et al. Serum haptoglobin levels in patients with melancholic and nonmelancholic major depression. Prog Neuropsychopharmacol Biol Psychiatry (2011) 35:944-7. doi:10.1016/j.pnpbp.2011.01.009

20. Irwin MR, Miller AH. Depressive disorders and immunity: 20 years of progress and discovery. Brain Behav Immun (2007) 21:374-83. doi:10.1016/j. bbi.2007.01.010

21. Euteneuer F, Schwarz MJ, Schmidmaier R, Hennings A, Riemer S, Stapf TM, et al. Blunted exercise-induced mobilization of monocytes in somatization syndromes and major depression. JAffect Disord (2014) 166:156-64. doi:10.1016/j.jad.2014.04.060

22. Dhabhar FS, Burke HM, Epel ES, Mellon SH, Rosser R, Reus VI, et al. Low serum IL-10 concentrations and loss of regulatory association between IL-6 and IL-10 in adults with major depression. J Psychiatr Res (2009) 43:962-9. doi:10.1016/j.jpsychires.2009.05.010

23. Song C, Halbreich U, Han C, Leonard BE, Luo H. Imbalance between pro- and anti-inflammatory cytokines, and between Th1 and Th 2 cytokines in depressed patients: the effect of electroacupuncture or fluoxetine treatment. Pharmacopsychiatry (2009) 42:182-8. doi:10.1055/s-0029-1202263

24. Parissis JT, Farmakis D, Nikolaou M, Birmpa D, Bistola V, Paraskevaidis I, et al. Plasma B-type natriuretic peptide and anti-inflammatory cytokine interleukin-10 levels predict adverse clinical outcome in chronic heart failure patients with depressive symptoms: a 1-year follow-up study. Eur J Heart Fail (2009) 11:967-72. doi:10.1093/eurjhf/hfp125

25. Holtzman S, Abbey SE, Chan C, Bargman JM, Stewart DE. A genetic predisposition to produce low levels of IL-10 is related to depressive symptoms: a pilot study of patients with end stage renal disease. Psychosomatics (2012) 53:155-61. doi:10.1016/j.psym.2011.10.001

26. Dantzer R, O'Connor JC, Freund GG, Johnson RW, Kelley KW. From inflammation to sickness and depression: when the immune system subjugates the brain. Nat Rev Neurosci (2008) 9:46-56. doi:10.1038/nrn2297

27. Voorhees JL, Tarr AJ, Wohleb ES, Godbout JP, Mo X, Sheridan JF, et al. Prolonged restraint stress increases IL-6, reduces IL-10, and causes persistent depressive-like behavior that is reversed by recombinant IL-10. PLoS One (2013) 8:e58488. doi:10.1371/journal.pone.0058488

28. Roque S, Correia-Neves M, Mesquita AR, Palha JA, Sousa N. Interleukin-10: a key cytokine in depression? Cardiovasc Psychiatry Neurol (2009) 2009:187894. doi:10.1155/2009/187894

29. Pan Y, Lin W, Wang W, Qi X, Wang D, Tang M. The effects of central proand anti-inflammatory immune challenges on depressive-like behavior induced by chronic forced swim stress in rats. Behav Brain Res (2013) 247:232-40. doi:10.1016/j.bbr.2013.03.031

30. Mesquita AR, Correia-Neves M, Roque S, Castro AG, Vieira P, Pedrosa J, et al. IL-10 modulates depressive-like behavior. J Psychiatr Res (2008) 43:89-97. doi:10.1016/j.jpsychires.2008.02.004

31. Ip WKE, Hoshi N, Shouval DS, Snapper S, Medzhitov R. Anti-inflammatory effect of IL-10 mediated by metabolic reprogramming of macrophages. Science (2017) 356:513-9. doi:10.1126/science.aal3535

32. Euteneuer F, Dannehl K, del Rey A, Engler H, Schedlowski M, Rief W. Immunological effects of behavioral activation with exercise in major depression: an exploratory randomized controlled trial. Transl Psychiatry (2017) 7:e1132. doi:10.1038/tp.2017.76
33. American Psychiatric Association. Diagnostic and Statistical Manual of Mental Disorders: DSM-IV. Washington, DC: American Psychiatric Association (1994).

34. Wittchen H-U, Wunderlich U, Gruschitz S, Zaudig M. Strukturiertes Klinisches Interview für DSM-IV, Achse I (SKID-I). (1997).

35. Ward LC. Comparison of factor structure models for the beck depression inventory - II. Psychol Assess (2006) 18:81-8. doi:10.1037/1040-3590.18.1.81

36. Hautzinger M, Kühner C, Keller F. Das Beck Depressionsinventar II. Deutsche Bearbeitung und Handbuch zum BDI II. Frankfurt: Harcourt Test Services (2006).

37. Craig CL, Marshall AL, Sjöström M, Bauman AE, Booth ML, Ainsworth BE, et al. International physical activity questionnaire: 12-country reliability and validity. Med Sci Sports Exerc (2003) 35:1381-95. doi:10.1249/01. MSS.0000078924.61453.FB

38. Grigoleit J, Kullmann JS, Wolf OT, Hammes F, Wegner A, Jablonowski S, et al. Dose-dependent effects of endotoxin on neurobehavioral functions in humans. PLOS ONE (2011) 6:1-10. doi:10.1371/journal.pone.0028330

39. Tabachnick B, Fidell F. Using Multivariate Statistics. Essex: Pearson (2014).

40. Faul F, Erdfelder E, Lang A-G, Buchner A. G*Power 3: a flexible statistical power analysis program for the social, behavioral, and biomedical sciences. Behav Res Methods (2007) 39:175-91. doi:10.3758/BF03193146

41. Bender R, Lange S. Adjusting for multiple testing - when and how? J Clin Epidemiol (2001) 54:343-9. doi:10.1016/S0895-4356(00)00314-0

42. Euteneuer F, Schwarz MJ, Hennings A, Riemer S, Stapf T, Selberdinger V, et al. Depression, cytokines and experimental pain: evidence for sexrelated association patterns. J Affect Disord (2011) 131:143-9. doi:10.1016/j. jad.2010.11.017

43. Demircan F, Gözel N, Kılınç F, Ulu R, Atmaca M. The impact of red blood cell distribution width and neutrophil/lymphocyte ratio on the diagnosis of major depressive disorder. Neurol Ther (2016) 5:27-33. doi:10.1007/ s40120-015-0039-8

44. Atli A, Demir S, Bulut $M$, Okan İbiloğlu A, Güneş $M$, Kaya $M$, et al. Neutrophil-lymphocyte ratio in patients with major depressive in patients with major depressive disorder undergoing no pharmacological therapy. Neuropsychiatr Dis Treat (2015) 11:2253. doi:10.2147/NDT.S89470

45. Smith PJ, Blumenthal JA, Babyak MA, Doraiswamy PM, Hinderliter A, Hoffman BM, et al. Intima-media thickness and age of first depressive episode. Biol Psychol (2009) 80:361-4. doi:10.1016/j.biopsycho.2008.11.001

46. Seldenrijk A, van Hout HPJ, van Marwijk HWJ, de Groot E, Gort J, Rustemeijer C, et al. Carotid atherosclerosis in depression and anxiety: associations for age of depression onset. World J Biol Psychiatry (2011) 12:549-58. doi:10.3109/ 15622975.2011.583942

47. Kendler KS, Fiske A, Gardner CO, Gatz M. Delineation of two genetic pathways to major depression. Biol Psychiatry (2009) 65:808-11. doi:10.1016/j. biopsych.2008.11.015

48. Kwilasz AJ, Grace PM, Serbedzija P, Maier SF, Watkins LR. The therapeutic potential of interleukin-10 in neuroimmune diseases. Neuropharmacology (2015) 96:55-69. doi:10.1016/j.neuropharm.2014.10.020

49. Krzyszton CP, Sparkman NL, Grant RW, Buchanan JB, Broussard SR, Woods J, et al. Exacerbated fatigue and motor deficits in interleukin10-deficient mice after peripheral immune stimulation. Am JPhysiol Regul Integr Comp Physiol (2008) 295:R1109-14. doi:10.1152/ajpregu. 90302.2008

Conflict of Interest Statement: The authors declare that the research was conducted in the absence of any commercial or financial relationships that could be construed as a potential conflict of interest.

Copyright (® 2017 Euteneuer, Dannehl, del Rey, Engler, Schedlowski and Rief. This is an open-access article distributed under the terms of the Creative Commons Attribution License (CC BY). The use, distribution or reproduction in other forums is permitted, provided the original author(s) or licensor are credited and that the original publication in this journal is cited, in accordance with accepted academic practice. No use, distribution or reproduction is permitted which does not comply with these terms. 